\title{
TRAVIS WILKERSON: HACIA UNA ARQUEOLOGÍA DE LA VIOLENCIA
}

\section{TRAVIS WILKERSON: TOWARDS AN ARCHAEOLOGY OF VIOLENCE}

\author{
Mariana Martínez Bonilla \\ Universidad Autónoma Metropolitana - Xochimilco, México \\ marianamtzbonilla@gmail.com
}

Recepción: 15 de febrero de 2019 • Aceptación: 5 de agosto de 2019

RESUMEN

El objetivo de este texto es reflexionar en torno a las maneras en que el cineasta norteamericano Travis Wilkerson (Denver, 1969) cuestiona, a partir de una revisión de la historia de la violencia racial en el sur de los Estados Unidos durante el siglo XX, el presente violento de dicha nación. Mediante los conceptos de política, archivo y montaje se analizará el ensayo fílmico Did You Wonder Who Fired the Gun?, de 2017, con el cual, Wilkerson interpela a la memoria del siglo pasado y logra conformar un particular discurso estético que reposa en la posibilidad de una historia alternativa, construida a través de la experimentación formal y narrativa, así como del trabajo de resignificación del material audiovisual, proveniente de diversas fuentes y archivos.

Palabras clave: memoria, historia, archivo, arqueología, montaje.
ABSTRACT

The main objective of this text is to reflect on the ways in which the North American filmmaker Travis Wilkerson (1969) questions, through the problematization of the history of racial violence in the South of the United States during the 2oth century, the violent present of that nation. Through some concepts such as politics, archive and montage, the the film essay Did You Wonder Who Fired the Gun? (2017) will be analyzed. In it, through formal and narrative experimentation, as well as the work of re-signification of the audiovisual material, coming from the most diverse sources and archives, the filmmaker interpellates directly to the memory of the past century and manages to shape a particular aesthetic discourse that rests on the possibility of an alternative history.

Keywords: memory, history, archive, archaeology, montage. 


\section{INTRODUCCIÓN}

Heredera de los preceptos estéticos y políticos del Agit-prop soviético y de El Tercer Cine latinoamericano, la obra del cineasta independiente Travis Wilkerson (Denver, 1969) posee un profundo sentido crítico sobre la historia de los Estados Unidos. A través de la actualización estética y narrativa de las intenciones políticas y revolucionarias de dichas corrientes, Wilkerson propone un "nuevo cine" cuya pregunta no sea por la manera en la cual sus imágenes son capaces de cambiar al mundo, sino "[...] que pretenda descubrir qué debería cambiar y cómo” (Wilkerson, 2007: s.p.).

Enmarcada en aquello que el artista llama Creative Agitation —agitación creativa一, y donde lo político y lo creativo deberán fusionarse, la obra de Wilkerson no admite adscripción alguna a esquemas, categorías o convenciones genéricas, a las cuales atraviesa intempestivamente. Según Wilkerson, las categorías de género sólo son útiles tanto para los agentes del comercio, como para aquellos cineastas alineados a la industria cinematográfica, como afirma en su texto Incomplete Notes on the Character of the New Cinema (2007).

En este sentido, podemos hablar de los procesos de experimentación formal y narrativa que caracterizan a su obra como un intento radical por "[...] acercar el arte a la política tanto como para que algún día la política pueda parecerse al arte" (Wilkerson, 2011: s.p.), con la finalidad de producir nuevos modos de la experiencia a través del uso significativo de la creatividad y las capacidades de la imaginación.

En las siguientes líneas, analizaré algunas estrategias utilizadas por Travis Wilkerson, en uno de sus más recientes filmes, Did you Wonder Who Fired the Gun? (2017), para problematizar la historia de la violencia racial en el sur de los Estados Unidos. Para ello, me interesa hacer énfasis tanto en los procesos de experimentación formal y narrativa, como en el trabajo de resignificación del material audiovisual a través del cual interpela directamente a la memoria del siglo pasado y logra conformar un particular discurso estético que potencia la posibilidad de una historia alternativa; es decir, una nueva manera para entender los conflictos del presente.

I

Did You Wonder Who Fired the Gun? (2017) es un ensayo documental, nacido como un performance e inspirado por la participación de Travis Wilkerson en la protesta organizada en el año 2013 en Los Angeles, California en honor de Trayvon Martin, un adolescente afroamericano asesinado en Florida por George Zimmerman en febrero del 2012. En él, el director indaga acerca de una oscura leyenda familiar: el rumor de que durante los años cuarenta del siglo pasado, su bisabuelo, Samuel Edwin - "S.E." - Branch, habría asesinado a sangre fría a Bill Cal Spann, un hombre afroamericano, en Dothan, Alabama.

Esta ominosa historia es relatada de una manera no lineal; los acontecimientos son reconstruidos fragmentariamente a través de una compleja combinación de material de archivo, perteneciente a las películas caseras de la familia materna de Wilkerson; entrevistas, documentos periciales e imágenes capturadas por el director.

Un par de secuencias extraídas del filme Matar a un ruiseñor, de Robert Mulligan (1962), teñidas de rojo mediante procesos de manipulación digital, dan inicio a un viaje de descenso hacia el infierno a partir de una historia enterrada en la memoria familiar que, sin embargo, es también el reflejo de la historia de una nación marcada por el odio y la violencia racial.

A través de ellas y en los anacronismos que comprometen, Wilkerson no sólo da cuenta de los estereotipos y las 
representaciones propias del cine clásico norteamericano, ${ }^{1}$ sino que establece una comparación entre dos patriarcas norteamericanos. Por un lado, nos encontramos con la figura de Atticus Finch, el héroe blanco de la novela Matar a un ruiseñor, de la escritora Harper Lee (1962) $)^{2}$ y, por el otro, con la de su bisabuelo, S.E. Branch, quien bien pudo formar parte de la horda - ataviada con sombreros Fedora-, que pretendía linchar a Tom Robbinson, el hombre afroamericano defendido por Finch en la novela de Lee, según palabras del propio Wilkerson.

La violencia ejercida por el cineasta sobre estas imágenes dotará al filme de una extrañeza inenarrable al tiempo que deviene, lenta y acompasadamente por su propia voz en off, en una búsqueda intersticial entre el entramado de los secretos familiares, de los que nadie quiere hablar, y la memoria colectiva, entendida como una serie de acontecimientos que importan sólo para determinados grupos sociales. Es decir, como aquella "[...] corriente de pensamiento continua [...] que retiene del pasado sólo lo que está vivo o es capaz de vivir en la conciencia del grupo que la mantiene" (Halbwachs,1995: 213), para revelar algunas de las causas del racismo en el sur de los Estados Unidos.

El análisis y la intervención plástica de la imagen de archivo se consolidan, desde el inicio del filme, como ejes analíticos a través de los cuales Wilkerson se ocupa del problema racial en los Estados Unidos, trazando en paralelo una genealogía que va de los inicios de la segregación hasta las manifestaciones más radicales del supremacismo blanco. Estas son imágenes e historias que, a partir de un método crítico

1 Según Antonio Weinrichter, la utilización de imágenes pertenecientes al cine narrativo comercial permite a los cineastas que trabajan con metraje encontrado estudiar las representaciones vehiculadas en dichos filmes. Véase Antonio Weinrichter. Metraje encontrado. La apropiación en el cine documental y experimental, p. 85.

2 Harper Lee. To Kill a Mockingbird. Philadeplhia: Lippincott. de análisis cercano a la microhistoria de Carlo Ginsburg y la pequeña escala de Siegfried Kracauer, desarrollado por Wilkerson, convergen en una búsqueda de las raíces del odio expresado por el racismo contemporáneo.

I I

En la obra de Wilkerson que aquí me ocupa, cada imagen es un cabo suelto dentro de una cadena de historias personales y colectivas, a través de la cual el pasado es citado a compadecer "[...] para que cese un poco la ceguera del presente [...], para cuestionar, también, los falsos "acontecimientos" de los que nuestra sociedad hace gala y con los que se embriaga para olvidar" (Didi-Huberman, 2016: 13).

Ante nosotros, a través del testimonio Ed Vaughn, circula la historia del activismo por los derechos humanos de las poblaciones de color, simbolizada por la heroica y olvidada figura de Rosa Parks. Pero también nos encontramos con los secretos pertenecientes a la infancia de la madre y la tía del cineasta; quienes en una entrevista relatan las complejidades y diferentes tonalidades de la vida de S.E. Branch, que van desde las memorias de un abuelo amoroso, hasta supuestas acciones pederastas.

Mediante la complejidad de la forma ensayística, Wilkerson realiza un trazado genealógico de la segregación sureña, al tiempo que excava en el pasado familiar para encontrar paralelos con aquellas otras historias de racismo e injusticia. Para ello, inicia con la contraposición entre el material del archivo familiar, recuperado de algunos rollos de película filmados por su abuelo en 1946, y las imágenes en blanco y negro, filmadas por él mismo, confrontando críticamente a la memoria colectiva y la historia familiar, como aquellas en donde Ed Vaughn, su madre y su tía, son entrevistados.

En una de las secuencias más significativas del filme, un grupo de imágenes en movimiento, extraídas de las películas 
caseras de $8 \mathrm{~mm}$, propiedad de la familia del artista, ocupa la totalidad de la pantalla. Estas imágenes, capturadas por el yerno de S.E. Branch, muestran a un grupo de hombres y mujeres conviviendo en el exterior de una casa durante un día soleado, configuran una especie de retícula, montada sobre un fondo negro.

Reproducidas en loop, dichas secuencias aparecen y desaparecen, dejando siempre espacios abiertos a la indeterminación que, a su vez, dan cuenta de los vacíos de la historia a la que el director está interpelando directamente. En dichos espacios, en esos momentos en los que la retícula parpadea y a través de las preguntas que el director plantea acerca del secreto que aquellas imágenes ocultan, se hacen visibles las tensiones y contradicciones de la historia familiar del director.

Sobre estos hiatos también se actualizan las relaciones de poder implicadas en el libre tránsito de los cuerpos, los gestos, las historias y los afectos en el espacio del fotograma. Cabe preguntarnos, ¿qué significa detener la imagen y arrancarla de su contexto original para multiplicarla y hacerla reverberar?

Al multiplicar las imágenes de las únicas 12 secuencias, dentro de la totalidad de filmaciones caseras de las que Wilkerson dispone, en las que S.E. Branch aparece, el cineasta nos invita a analizar el instante en el cual el gesto de su bisabuelo se transforma. Así pues, nos indica la existencia de un punctum, de "[...] un $<<$ gesto $>>$ imprevisto al que reconocemos $<<$ un valor de vida $>>$, porque libera a la imagen de lo que tiene en común - por su fijación - con lo generalizado y gregario", como afirma Josep Casals (2015: 38-39) a propósito del análisis de Roland Barthes sobre el cuerpo como el punto "magnético" y neurálgico, sobre el que se abre el abismo de significación de las imágenes fotográficas que analiza en La cámara lúcida (1990).

En esta multitud de cortes que no cesan de repetirse, operados sobre el amplio corpus del archivo familiar, atendemos plenamente a la mutación de un andar enrarecido y una mirada incómoda y esquiva, mostradas en una cinta en blanco y negro filmada durante octubre de 1946 - mes del asesinato de Bill C. Spann-, "en una inconfundible arrogancia" (Wilkerson, 2017), tal y como lo muestra la cinta a color filmada en 1953. Me pregunto si este andar envalentonado y arrogante, pudiera cristalizar el gesto social que acepta y normaliza la violencia racial.

I I

En su libro Shadows, Specters, Shards: making History in AvantGarde Film (2005), Jeffrey Skoller afirma que la historia crea sus narrativas a partir de los fragmentos arrancados a aquello que queda después de que un evento ha ocurrido. De la misma manera, el cine reconstruye el tiempo a través de una serie de tomas, cada una de ellas "[...] un fragmento incompleto cortado del tiempo continuo" (Skoller, 2005: VXI), a través de ciertas configuraciones formales que le permiten reconstruir la supuesta linealidad temporal del acontecer, escondiendo este carácter fragmentario.

El cine experimental, de vanguardia y ensayístico, al contrario, se empeña en enfatizar "[...] el fragmento como un elemento central del pensamiento histórico y cinematográfico. El sentido se acumula través de la constelación de piezas y fragmentos y los espacios entre ellos" (Skoller, 2005: XVI). Siguiendo esta premisa, es posible afirmar que, a través de la fragmentación narrativa y la figuración disruptiva tanto de la historia como de las imágenes, Wilkerson irrumpe performáticamente en el archivo - tanto familiar como oficial- no sólo para cuestionarlo, como se ha mencionado anteriormente, sino para yuxtaponer los tiempos y las memorias, elaborando una

3 Jeffrey Skoller. Shadows, Specters, Shards. Making History in AvantGarde Film. Minneapolis: university of Minnesota Press. 
compleja genealogía de la violencia racial en el sur de los Estados Unidos.

Su posicionamiento crítico lo obliga no sólo a indagar en la complejidad y los matices de la personalidad de S.E. Branch y su familia, sino también en las tensiones de los procesos sociales a través de los cuales los crímenes raciales tienen lugar. Tal es el caso de la contraposición entre las memorias de su familia, en donde su bisabuelo juega un papel fundamental, y aquella memoria de la historia herida en la que se inscribe el asesinato de Bill Spann.

A través de una pantalla dividida en la que se muestran dos pares de secuencias que capturan los momentos de la vida cotidiana familiar — hombres y mujeres posando frente a una casa, por una parte $y$, por la otra, una pequeña niña caminando y mirando fijamente a la cámara mientras sonríe-, y la inscripción de la lectura detallada del certificado de defunción de Spann, Wilkerson pone en evidencia las aporías propias de la memoria y del relato histórico.

"No puedes ver estas imágenes del mismo modo después de haberlo leído" (Wilkerson, 2017), asegura el realizador y así, a partir de esta toma de posición mediada por el montaje, asistimos a la movilización de la contraposición entre el campo sonoro, o la voz que habla, y el campo visual, aquellas imágenes del archivo familiar, como un dispositivo crítico y dialéctico en donde se vuelve imposible atender a la representación de los momentos familiares alrededor de S.E. Branch omitiendo la información sobre el asesinato de Bill Span, otorgada por la voz del cineasta.

En esta confrontación entre archivos — atravesados a su manera por ciertas lógicas del poder y del silencio-, así como en la fractura narrativa que impera a lo largo de todo el filme, encontramos una suspensión de la significación que da cuenta del carácter abiertamente político del "nuevo cine" de Wilkerson, pues este "[...] sólo puede existir en un estado tan indeterminado e incompleto como el mundo al que pretende reflejar" (Wilkerson, 2007).

Lo que se presenta es una ruptura de orden brechtiano, un “montaje de la complejidad", como afirma Georges Didi-Huberman (2013) en su análisis sobre el Diario de trabajo de Brecht. Es decir, un distanciamiento que, a través de la sustitución de las progresiones lineales, propias del modelo narrativo clásico por una ruptura radical tanto de la forma como del contenido, tiende a dar cuenta de las contradicciones inherentes a una determinada situación socio-política.

En ese sentido, la disociación del relato, su ruptura a través de la separación entre lo que las imágenes muestran y lo que la voz dice, opera como una dislocación del sentido que da cuenta de la capacidad que las imágenes poseen para operar desde su singularidad. Éstas cuentan su propia historia y, al permitirles hablar, Wilkerson ejecuta un doble ejercicio arqueológico.

Por un lado se acerca al pasado a través de la búsqueda de los vestigios y los restos materiales de la sociedad sureña norteamericana y, por el otro, se aproxima al archivo que conforman, desde una arqueología a contracorriente, como la planteada por Michel Foucault en su Arqueología del saber (1969), ${ }^{4}$ para interrogarlos en el plano de su aparición, para preguntar por las condiciones de posibilidad que permiten su legibilidad en una época determinada.

IV

Al excavar en el archivo familiar, en su carácter fantasmal, indiscernible, problemático e incompleto $\mathrm{y}$, más aún, cuando esas fotografías y videos familiares son puestos en relación con la historia de una nación profundamente marcada por la

4 Michel Foucault. Arqueología del Saber. México: Siglo XXI. 
violencia, ¿a qué clase de espectros se está convocando?, ¿qué órdenes del tiempo y de la historia entran en operación en dicha invocación, en ese espacio intersticial entre la memoria personal y la colectiva?

Es a través del montaje, en tanto articulación disruptiva y configuración conceptual de la operación de recuperación de la memoria y en tanto confrontación histórica, que Travis Wilkerson invoca al pasado y a sus fantasmas. El cineasta llama una vez más nuestra atención para reflexionar sobre la naturaleza estructural —es decir, social y política- del racismo al establecer un complejo diálogo con las manifestaciones contemporáneas de la supremacía blanca.

Las imágenes en blanco y negro de la ceremonia de la Confederación en Verbena a la que el cineasta asiste, intentando encontrarse con su tía, una lideresa supremacista, dan cuenta de la relación entre la injusticia y la violencia raciales y la negación de la participación de los esclavos negros como combatientes en la Guerra Civil. En este memorial, como afirmara el propio Wilkerson, "esas vidas no importan". De la misma manera, el pueblo de Montgomery ha olvidado a Rosa Parks y los habitantes de Lewisville han suprimido cualquier información acerca del paradero del sepulcro de Bill Spann.

En este riguroso ejercicio audiovisual acerca de la memoria, en esta práctica de "justeza" sobre una cuestión de justicia, el cineasta también rememora a todos aquellos hombres y mujeres afroamericanos, víctimas de crímenes relacionados con el odio racial; sujetos que, al igual que Bill Spann y Trayvon Martin, fueron asesinados sin que nadie resultara culpable por sus muertes, y cuyos nombres circulan, uno tras otro sobre la canción de protesta Hell You Talmabout (2013), interpretada por Janelle Monáe y Wondaland Records, exigiendo ser nombrados, en las brevísimas secuencias de intertítulo que articulan y desarticulan toda la lógica narrativa del filme.
De modo que, esta historia del racismo en el sur de los Estados Unidos, contada a contrapelo, se convierte también en un lamento, que plantea una serie de preguntas - con énfasis en los acontecimientos de un pasado corrupto-, que se empeñó rotundamente en invisibilizarlos, y ante las cuales no es posible ofrecer respuestas concretas o satisfactorias.

Por lo tanto, la pregunta que Travis Wilkerson plantea cuando alude, en el título del filme a la canción que Phil Ochs compuso en 1963 en honor de William Moore, ${ }^{5}$ no es sobre el quién, pues la verdad acerca del crimen S.E. Branch es nebulosa, sino acerca del por qué, acerca de la raíz de los problemas del presente, de los acontecimientos que sistemáticamente han quedado en el olvido.

Finalmente, el ejercicio arqueológico que Did You Wonder Who Fired the Gun? (2017) supone no es sobre lo personal, sino sobre lo colectivo y las maneras en las que la violencia se inscribe en la memoria histórica. En el ensayo audiovisual aquí analizado, a la manera de la literatura menor, caracterizada por Kafka, y analizada detenidamente por G. Deleuze y F. Guattari en Kafka, por una literatura menor, el problema familiar, se conecta con lo político; es decir, "[...] el problema individual, se vuelve entonces tanto más necesario, indispensable, agrandado en el microscopio, cuanto que es un problema muy distinto en el que se remueve en su interior" (Deleuze y Guattari, 2008: 29).

En el ejercicio ensayístico de Travis Wilkerson, la oscuridad alrededor de la historia familiar, el secreto del asesinato cometido por su bisabuelo, se piensa como un punto clave, como una pista - en el sentido que Carlo Ginsburg le otorgó a la palabra- que debe ser investigada; esto supone una extrañeza - una marca aporética dentro de la continuidad del relato

5 Phil Ochs. "William Moore". En A Toast to Those Who Are Gone [CD] Rhino. 
familiar - que necesita ser explicada en tanto su peculiaridad debe ser " $[. .$.$] tomada como un signo de una estructura mayor,$ pero escondida o desconocida” (Peltonen, 2001: 349). De tal manera que nos permita recuperar la memoria de una nación, y así, desde esa otra historia y desde el lugar de resistencia que ésta significa, sea posible comprender el presente.

\section{REFERENCIAS}

Barthes, R. (1990). La cámara lúcida. Nota sobre fotografía. Barcelona: Paidós.

Casals, J. (2015). Constelación de pasaje. Imagen, experiencia, locura. Barcelona: Anagrama.

Deleuze, G. y Guattari, F. (1978). Kafka, por una literatura menor. México: Ediciones Era.

Didi-Huberman, G. (2013). Cuando las imágenes toman posición. España: A. Machado Libros.

Didi-Huberman, G. (2016). Pasados Citados por Jean-Luc Godard. Santander: Shangrila.

Halbwachs, M. y Lasén, A. (1995). "Memoria colectiva y memoria histórica”. En Reis: Revista Española de Investigaciones Sociológicas, núm. 69, pp. 209-219.

Peltonen, M. (2001). “Clues, Margins and Monads: The Micho-Macro Link in Historical Research". En History and Theory, vol. 40, núm. 3, pp. 347-359.

Skoller, J. (2005). Shadows, Specters, Shards. Making History in AvantGarde Film. Minneapolis: university of Minnesota Press.

Weinrichter, A. (2009). Metraje encontrado. La apropiación en el cine documental y experimental. Navarra: Fondo de publicaciones del Gobierno de Navarra.

Wilkerson, T. (2007). "Incomplete notes on the Character of New Cinema”. En Kino. Disponible en: http://www.e-kino.si/2007/no-1/ blazinice/incomplete-notes-on-the-character-of-the-new-cinema

Wilkerson, T. (2011). Creative Agitation. Disponible en: https://docs. wixstatic.com/ugd/8598f7_25a11fe2908042bb8c776457a8984107.pdf Wilkerson, T. (dir.) (2017). Did You Wonder Who Fired the Gun? [DVD]. Estados Unidos. 